with higher pre-bronchodilator $\mathrm{FEV}_{1}$ improvement at end of QUEST experienced fewer exacerbations during both studies. Over $80 \%$ of patients who achieved $\geq 100 \mathrm{~mL}$ or $\geq 200 \mathrm{~mL}$ pre-bronchodilator $\mathrm{FEV}_{1}$ improvements at the end of QUEST maintained these improvements in TRAVERSE.

Conclusions Greater improvements in pre-bronchodilator $\mathrm{FEV}_{1}$ in QUEST led to long-term enhanced benefits of dupilumab treatment; patients maintained these improvements and had fewer exacerbations during TRAVERSE.

Please refer to page A189 for declarations of interest related to this abstract.

\section{S87 SEVERE ASTHMA OUTCOMES WHEN SWITCHING FROM MEPOLIZUMAB TO BENRALIZUMAB IN NON- RESPONDERS WITH PERSISTENT SPUTUM EOSINOPHILIA}

G Tavernier, M Philbin, LJ Holmes, L Elsey, D Allen, S Fowler. Manchester University NHS Foundation Trust, Manchester, UK

\subsection{6/thorax-2021-BTSabstracts.93}

Background Anti-IL-5 monoclonal antibodies reduce systemic corticosteroid use and exacerbation rate in severe eosinophilic asthma. Although their specific mechanisms of action differ, there is as yet no guidance on whether to choose mepolizumab or benralizumab for any given patient.

Aims To investigate clinical outcomes of patients switching to benralizumab after non-response to mepolizumab associated with persistent sputum eosinophilia.

Methods We recruited patients who failed to respond to mepolizumab over 12 months (no meaningful reduction in maintenance steroid use and/or exacerbation rate), with sputum eosinophils above the threshold of $2 \%$.

Over the subsequent 12 months of benralizumab treatment we recorded daily prednisolone dose, ACQ6, AQLQ, and sputum \& blood eosinophils. Lung function and FeNO testing was severely impacted by the COVID pandemic.

Results Fifty-three of 165 (32\%) mepolizumab patients were identified as candidates for a switch of therapy with residual positive sputum eosinophils, of which 36 have completed 12 months of treatment, 20 with available sputum eosinophil results. Five patients stopped therapy before a full year (two for failure to respond to treatment at 6-9 months, one allergic reaction, two unspecified).

\begin{tabular}{|c|c|c|c|c|}
\hline $\begin{array}{l}\text { Clinical parameter } \\
\text { Median (IQR) or mean (SD) }\end{array}$ & $\mathbf{n}$ & \begin{tabular}{|l} 
Prior to \\
benralizumab
\end{tabular} & $\begin{array}{l}12 \text { months } \\
\text { benralizumab }\end{array}$ & $\begin{array}{l}\text { Paired test } \\
p \text { value }\end{array}$ \\
\hline OCS $\delta \mathrm{mg} / \mathrm{d}$, median (IQR) & 33 & $4(10)$ & $5(7.5)$ & 0.101 \\
\hline $\begin{array}{l}\text { Annual exacerbations } \delta \text {, } \\
\text { mean (SD) }\end{array}$ & 25 & $4.5(5.5)$ & $2(5)$ & 0.010 \\
\hline $\begin{array}{l}\text { Sputum \% eosinophils } \delta \text {, } \\
\text { median (IQR) }\end{array}$ & 20 & $8.5(15)$ & $0(0)$ & $<0.001$ \\
\hline ACQ6 $\delta$, mean (SD) & 33 & $2.8(1.7)$ & $2.3(1.5)$ & 0.046 \\
\hline$A Q L Q \beta$, mean (SD) & 28 & $3.3(1.8)$ & $4.0(2.1)$ & 0.033 \\
\hline $\begin{array}{l}\text { ICS } \delta \text { mcg BDP equivalent / d, } \\
\text { median (IQR) }\end{array}$ & 33 & $2000(1200)$ & $1840(400)$ & 0.753 \\
\hline $\begin{array}{l}\text { Blood eosinophils } \beta \\
10^{*} 9 \text { cells/ml- median (IQR) }\end{array}$ & 30 & $0.09(0.11)$ & $0(0.00)$ & 0.001 \\
\hline
\end{tabular}

Clinical parameters measured at time of decision to switch from mepolizumab or benralizumab $(\delta)$ or benralizumab baseline visit $(\beta)$ and after 12 months on benralizumab.
After 12 months on benralizumab, all patients had negative sputum eosinophils as well as improvements in ACQ6, AQLQ, blood eosinophils and reduced exacerbation rate compared to before switching (table 1).

Conclusions Around a third of patients failed to respond to mepolizumab and displayed persistent airway eosinophilia. All of these patients had complete suppression of sputum eosinophils on benralizumab with significant clinical improvements in exacerbation rate, blood eosinophils, asthma control and quality of life. These real-life observations in our severe asthma patient population confirm the results of the SIROCCO and Calima trials.

\section{S88 USE OF A CONNECTED INHALER SYSTEM IN THE PRE- BIOLOGIC ASSESSMENT OF PATIENTS WITH SEVERE ASTHMA}

${ }^{1} \mathrm{~J}$ Holmes, ${ }^{2} \mathrm{P}$ Dennison, ${ }^{3} \mathrm{D}$ J Jackson, ${ }^{3} \mathrm{G}$ D'Ancona, ${ }^{4} \mathrm{~A}$ Mansur, ${ }^{5} \mathrm{~A}$ Menzies-Gow, ${ }^{5} \mathrm{P}$ Patel, ${ }^{6} \mathrm{P}$ Pfeffer, ${ }^{6} \mathrm{C}$ Chen, ${ }^{7} \mathrm{D}$ Shaw, ${ }^{8}$ Propeller Health, ${ }^{1} \mathrm{LG}$ Heaney. ${ }^{1}$ Queen's University Belfast, Belfast, UK; ${ }^{2}$ University Hospital Southampton NHS Foundation Trust, Southampton, UKi ${ }^{3}$ Guys and St Thomas NHS Foundation Trust, London, Belfast; ${ }^{4}$ Heartlands Hospital Birmingham, UK; ${ }^{5}$ Royal Brompton Hospital, London, UK; ${ }^{6}$ St Bartholomews Hospital, London, UK; ${ }^{7}$ Nottingham City Hospital, Nottingham, UK; ${ }^{8}$ Propeller Health, Madison, WI, USA

\subsection{6/thorax-2021-BTSabstracts.94}

Background Sub-optimal adherence is a significant factor in patients with difficult to treat asthma. Aligning adherence to maintenance inhaled corticosteroid (ICS) treatment with digital inhaler monitoring and measurement of fractional exhaled nitric oxide (FeNO suppression) can rapidly differentiate patients with poor adherence from those who require treatment escalation with type- 2 biologic therapy. ${ }^{1}$

Objectives To assess the feasibility and utility of monitoring adherence using a digital connected inhaler system (CIS) embedded within the patient pathway as a service evaluation, to rapidly identify patients for initiation of biologic therapies in UK specialist severe asthma clinics $n=7$ ).

Methods Using a CIS (Propeller Health) patients completed adherence monitoring/biomarker profiling for 1 month as part of a pre-biologic assessment followed by clinical decision (initiate biologic therapy or continue monitoring - figure 1). Patients had the following assessments at baseline and 1 month follow-up: spirometry, FeNO, peripheral blood eosinophil count and asthma control questionnaire (ACQ-7).

Results To date, 104 patients have been initiated on the CIS with 43 having outcome data at 3 months. In FeNO-high subjects $(\mathrm{FeNO} \geq 45 \mathrm{ppb}, \mathrm{n}=26)$ median adherence was $100 \%$ (range $57-100 \%$ ) and there were significant reductions in ACQ-7 (2.88 vs 2.14, p $=0.03)$ and FeNO (63ppb vs $32 \mathrm{ppb}, \mathrm{p}<0.001)$ between baseline and 1 month follow-up. In patients with positive FeNO suppression ${ }^{1}(n=16), 14$ maintained good adherence with no rescue prednisolone, 2 were commenced on a biologic therapy and 2 had persistent poor adherence. In those with negative FeNO $\operatorname{suppression}^{1}(n=10)$, 6 were commenced on a biologic therapy at 3 months, with 4 having good adherence with ongoing monitoring. In FeNOlow subjects $(\mathrm{FeNO}<45 \mathrm{ppb}, \mathrm{n}=17)$, median adherence was $100 \%$ (range $85-100 \%$ ) but no differences in parameters were seen at 1 month, consistent with previous data supporting this 'cut-point' to identify difficult to treat asthma patients with poor ICS adherence. ${ }^{1}$

Conclusion Using a CIS in conjunction with FeNO monitoring is a useful method for assessing adherence to ICS when 